\title{
Serum 25-Hydroxyvitamin D Level and Aortic Intima-Media Thickness in Patients Without Clinical Manifestation of Atherosclerotic Cardiovascular Disease
}

\author{
Gülhan Yüksel Kalkan, ${ }^{1 *}$ Mustafa Gür, ${ }^{2}$ Nermin Yıldız Koyunsever, ${ }^{1}$ Taner Şeker, ${ }^{1}$ \\ Mehmet Yavuz Gözükara, ${ }^{3}$ Hakan Uçar, ${ }^{1}$ Onur Kaypaklı, ${ }^{1}$ Ahmet Oytun Baykan, ${ }^{1}$ \\ Selehattin Akyol, ${ }^{1}$ Caner Türkoğlu, ${ }^{1}$ Zafer Elbasan, ${ }^{1}$ Durmuş Yıldıray Şahin, ${ }^{1}$ \\ and Murat Çaylı ${ }^{1}$ \\ ${ }^{1}$ Adana Numune Training and Research Hospital, Department of Cardiology, Adana/Turkey \\ ${ }^{2}$ Kafkas University, School of Medicine, Department of Cardiology, Kars, Turkey \\ ${ }^{3}$ Department of Internal Medicine, Mersin State Hospital, Mersin, Turkey
}

\begin{abstract}
Objectives: Existing evidence suggests that impaired vitamin D metabolism contribute to the development of atherosclerosis. Aortic intima-media thickness (IMT) is an earlier marker than carotid IMT of preclinical atherosclerosis. However, there is a lack of researches on direct investigation of relevance between serum 25hydroxyvitamin $\mathrm{D}(25(\mathrm{OH}) \mathrm{D})$ and thoracic aortic IMT. In this study, we aimed to assess the relationship between thoracic aortic IMT and 25(OH)D. Methods: We studied 117 patients (mean age: $45.5 \pm$ 8.4 years) who underwent transesophageal echocardiography (TEE) for various indications. Serum 25(OH)D was measured using a direct competitive chemiluminescent immunoassay. The patients were divided into three groups according to the their serum 25(OH)D levels (VitD deficiency , VitD $D_{\text {insufficient }}$ and $V_{i t D_{\text {normal }}}$ groups). TEE was performed
\end{abstract}

Key words: Vitamin D; intima-media; CRP; echocardiography in all subjects. High sensitive C-reactive protein (hsCRP) and other biochemical markers were measured using an automated chemistry analyzer. Results: Only $24.8 \%$ (29 patients) of patients had normal levels of 25(OH)D. The highest aortic IMT values were observed in $V_{i t D}$ deficiency group compared with $\mathrm{VitD}_{\text {insufficient }}$ and $\mathrm{Vit} \mathrm{D}_{\text {normal }}$ groups ( $P<0.05$, for all). Also aortic IMT values of $\mathrm{VitD}_{\text {insufficient }}$ group were higher than VitD ${ }_{\text {normal }}$ group $(P<0.05)$. 25(OH)D was independently associated with hs-CRP $(\beta=-0.442, P<0.001)$ and aortic IMT $(\beta=-0.499, P<0.001)$. Conclusions: The lower 25(OH)D level was independently associated with higher aortic IMT values. Therefore, hypovitaminosis $D$ may have a role on pathogenesis of subclinical thoracic atherosclerosis. J. Clin. Lab. Anal. 29:305311, 2015. (c) 2014 Wiley Periodicals, Inc.

\section{INTRODUCTION}

Vitamin D insufficiency and deficiency are now recognized as a global problem, affecting a large percentage of the general population (1). A growing evidence shows that populations who are deficient in 25-hydroxyvitamin $\mathrm{D}(25(\mathrm{OH}) \mathrm{D})$ have higher risks for several cardiovascularrelated disorders such as diabetes mellitus (2), obesity (3), hypertension (4), carotid arterial disease (5), impaired arterial stiffness (6), myocardial infarction (7), heart failure (8), and ultimately mortality (9). Previous studies showed that vitamin $D$ deficiency affects vascular function by augmenting atherosclerosis, while treatment with vitamin D is protective (10). Also, recent studies have indicated that $25(\mathrm{OH}) \mathrm{D}$ is involved in the pathophysiologic process of atherosclerosis (11).

Although there have been numerous studies on the association between serum $25(\mathrm{OH}) \mathrm{D}$ and the diseases of

\footnotetext{
*Correspondence to: Gülhan Yüksel Kalkan, Adana Numune Education and Research Hospital, Department of Cardiology, Zip code; 01170, Adana/Turkey. E-mail: gulhankalkan@yahoo.com.tr
}

Received 6 October 2013; Accepted 2 April 2014

DOI 10.1002/jcla.21770

Published online in Wiley Online Library (wileyonlinelibrary.com). 
cardiovascular system (2-11) in the recently, there is lack of researches on direct investigation of relevance between serum 25(OH)D and thoracic aortic intima media thickness (IMT). Whereas, aortic atherosclerotic lesions detected on transesophageal echocardiography (TEE) are markers of diffuse atherosclerotic disease $(12,13)$ and thoracic aortic IMT has been reported as an earlier marker of preclinical atherosclerosis than carotid IMT(14).

The association between thoracic aortic IMT and serum $25(\mathrm{OH}) \mathrm{D}$ level remains to be investigated in humans. Therefore, in the present study, we aimed to assess the relationship between thoracic aortic IMT and serum $25(\mathrm{OH}) \mathrm{D}$ level in patients undergoing TEE examination for various indications.

\section{METHODS}

\section{Study Populations}

Between June 2012 and June 2013 we evaluated 117 patients who had non-atherosclerotic heart disease and underwent TEE examination for various indications (67 male, 50 female and mean age; $41.6 \pm 11.3$ years) such as evaluation and management of lone atrial fibrillation (26 patients), valvular heart disease (ten patients for mitral valve disease, seven patients for bicuspid aortic valve) and suspected atrial septal defect (74 patients). The patients were classified into three groups according to serum 25(OH)D levels(15): VitD deficiency group $(<20 \mathrm{ng} / \mathrm{ml}, n=$

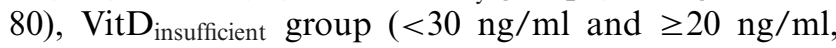
$n=56)$ and VitD $\mathrm{D}_{\text {normal }}$ group ( $\left.\geq 30 \mathrm{ng} / \mathrm{ml}, n=29\right)$. One hundred and seventy of 413 patients who underwent TEE examination within one year were included in the study. Eighty-five patients with known coronary artery disease (positive history or clinical signs of ischemic heart disease), peripheral vascular disease, carotid artery surgery, or stroke, and 120 patients who had hypertension, diabetes mellitus, and smokers were excluded from the study. We also excluded 47 patients with familial hypercholesterolemia, aortic dissection or aortic aneurysm, aortic regurgitation, aortic stenosis, as well as 44 patients with poor ultrasonographic recording quality with no clear delineation of the intima-media complex. In addition, patients taking any medication and positive exercise treadmill test were also excluded from the study. Institutional ethics committee approved the study and written informed consent for participation in the study was obtained from all individuals. Age and gender were recorded. Body mass index (BMI) was computed as weight divided by height squared $\left(\mathrm{kg} / \mathrm{m}^{2}\right)$.

\section{Blood Sampling}

Blood samples were obtained following an overnight fasting state just before TEE examination. Blood sam- ples were centrifuged at $5,000 \times g$ for $10 \mathrm{~min}$ for plasma separation. Plasma samples were stored at $-70^{\circ} \mathrm{C}$ for the analysis of serum $25(\mathrm{OH}) \mathrm{D}$, high sensitive C-reactive protein (hSCRP), triglyceride, total cholesterol, low-density lipoprotein (LDL), high-density lipoprotein (HDL), creatinine, and fasting glucose.

Hs-CRP was measured with an autoanalyzer (Aeroset) by using a commercial spectrophotometric kit (Scil Diagnostics $\mathrm{GmbH}$, Viernheim, Germany). Serum calcium $(8.2-10.2 \mathrm{mg} / \mathrm{dl})$ and parathyroid hormone levels were measured in all subject.

Serum 25(OH)D was measured using a direct competitive chemiluminescent immunoassay (Elecsys; Roche Diagnostics, Mannheim, Germany). Within-run coefficient of variation $(\mathrm{CV})$ was $7.6-11.3 \%$ and total imprecision $\mathrm{CV}$ was $6.9-10.1 \%$.

\section{Transthoracic and Transesophageal Echocardiography}

Transthoracic echocardiography and TEE were performed in all study subjects by using a commercially available system (Vivid $7^{\circledR}$, GE Medical Systems, Horten, Norway). Left ventricular ejection fraction (EF) was determined by modified Simpson's method (16). All patients underwent TEE by using a $5 \mathrm{Mhz}$ multiplane transesophageal transducer after a 4-h fasting period prior to the procedure. Subjects were placed in left decubitus with the left arm under the head, which was kept in a flexed position after oropharyngeal anesthesia with lidocaine spray. The transducer was introduced for visualization of the cardiac and aortic structures into the esophagus and gastric cavity through the mouth. An experienced cardiologist blinded to other laboratory results performed TEE. TEE was well tolerated by all patients, and there were no complications. All studies were recorded and were interpreted independently by an experienced observer.

Thoracic aortic IMT was defined as the distance from the leading edge of the lumen-intima interface to the leading edge of the media-adventitia interface of the far wall. The measurement of IMT in the thoracic aorta was made manually in six separate segments (length of 1 segment $5 \mathrm{~cm}$ ): ascending aorta, arch, from 0 to $5 \mathrm{~cm}$ distal to the arch, from 5 to $10 \mathrm{~cm}$ distal to the arch, from 10 to $15 \mathrm{~cm}$ distal to the arch, and from 15 to $20 \mathrm{~cm}$ distal to the arch. The maximum IMT was measured in each segment and the mean value for the maximum IMT among the 6 segments was taken as the evaluable IMT of the thoracic aorta (17). The sample measurement of thoracic aortic IMT was showed in Fig. 1.

\section{Statistical Analysis}

All analyses were conducted using SPSS 17.0 (SPSS for Windows 17.0, Chicago, IL, USA). Comparison of 


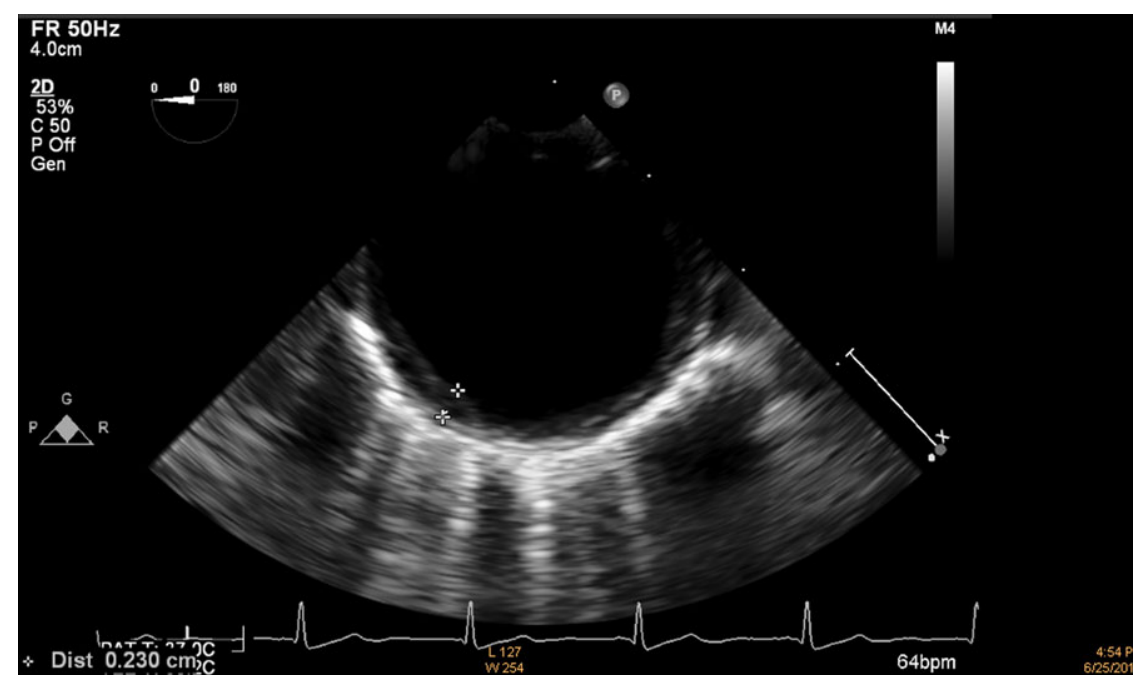

Fig. 1. The sample measurement of thoracic aortic intima media thickness.

categorical variables between the groups was performed using the chi-square test. Analysis of variance (ANOVA) was used in the analysis of continuous variables. Analysis of normality was performed with the KolmogorovSmirnov test. A stratified post hoc analysis of echocardiographic, clinical, and laboratory variables were performed according to serum $25(\mathrm{OH}) \mathrm{D}$ levels. The correlations between serum 25(OH)D and aortic IMT, clinical, laboratory parameters were assessed by the Pearson correlation test. Multiple linear regression analysis was performed to identify the independent associations of serum 25(OH)D levels. A 2 -tailed $P<0.05$ was considered statistically significant.

\section{Reproducibility}

Aortic IMT measurements were repeated by the second observer and interobserver variability was calculated as the difference in two measurements of the thirty patient by observer divided by the mean value. Interobserver variability's were $8.6 \%$.

\section{RESULTS}

Mean vitamin D value was $24.8 \pm 9.9 \mathrm{ng} / \mathrm{ml}$; deficient and insufficient $25(\mathrm{OH}) \mathrm{D}$ levels were observed at $40.2 \%$ $(n=47)$ and $35.0 \%(n=41)$ in patients, respectively. Serum $25(\mathrm{OH}) \mathrm{D}$ level was normal at only $24.8 \%(n=29)$ of patients.

\section{Baseline Characteristics (Table 1)}

Triglyceride and creatinine values were different among the groups $(P<0.05$, for all). The highest hs-CRP values were observed in VitD $_{\text {deficiency }}$ group compared with
$\operatorname{VitD}_{\text {insufficient }}$ and $\mathrm{VitD}_{\text {normal }}$ groups $(P<0.05$, for all). Moreover, hs-CRP values of $V_{i t} D_{\text {insufficient }}$ group were higher than $\operatorname{VitD}_{\text {normal }}$ group $(P<0.05)$. Parathyroid hormone levels of $\mathrm{VitD}_{\text {deficiency }}$ and $\mathrm{Vit}_{\text {insufficient }}$ groups were higher than $\operatorname{VitD}_{\text {normal }}$ group $(P<0.05$, for all).

\section{Thoracic Aortic Intima Media Thickness (Table 1)}

The highest aortic IMT values were observed in VitD $D_{\text {deficiency }}$ group compared with VitD $_{\text {insufficient }}$ and VitD $_{\text {normal }}$ groups $(P<0.05$ for all). Also, aortic IMT values of VitD $\mathrm{D}_{\text {insufficient }}$ group were higher than $\mathrm{VitD}_{\text {normal }}$ group $(P<0.05)$.

\section{Bivariate and Multivariate Relationships of 25(OH)D}

Bivariate and multivariate relationships of $25(\mathrm{OH}) \mathrm{D}$ were demonstrated in Table 2. Serum 25(OH)D was found to be associated with BMI $(r=-0.315, P=0.001), \mathrm{LDL}$ cholesterol level $(r=-0.187, P=0.044)$, triglyceride level $(r=-0.227, P=0.014)$, hs-CRP $(-0.553, P<0.001)$, aortic IMT $(r=-0.612, P<0.001)$ in bivariate analysis. The relationships between $25(\mathrm{OH}) \mathrm{D}$ with aortic IMT and hs-CRP were shown in Figs. 2 and 3. Multivariate linear regression analysis showed that $25(\mathrm{OH}) \mathrm{D}$ was independently related with hs-CRP $(\beta=-0.442, P<0.001)$ and aortic IMT $(\beta=-0.499, P<0.001)$.

\section{DISCUSSION}

To our knowledge this is the first study that investigated the relationship between $25(\mathrm{OH}) \mathrm{D}$ level and IMT of thoracic aorta in patients without clinical manifestation of atherosclerotic cardiovascular disease. Our results 
TABLE 1. Comparison of Baseline, Laboratory, Echocardiographic, and Clinical Characteristics

\begin{tabular}{|c|c|c|c|c|}
\hline Variables & $\begin{array}{l}\text { VitD }_{\text {deficiency }} \\
\text { group }(n=47)\end{array}$ & $\begin{array}{l}\text { VitD }_{\text {insufficient }} \\
\text { group }(n=41)\end{array}$ & $\begin{array}{c}\text { VitD }_{\text {normal }} \\
\text { group }(n=29)\end{array}$ & $P$-value \\
\hline \multicolumn{5}{|l|}{ Baseline Characteristics } \\
\hline Age (years) & $43.5 \pm 12.2$ & $39.0 \pm 9.6$ & $42.3 \pm 11.7$ & 0.176 \\
\hline Gender $(\text { male })^{\mathrm{X}}, \%$ & $26(55.3 \%)$ & $24(58.5 \%)$ & $17(58.6 \%)$ & 0.758 \\
\hline $\mathrm{BMI}, \mathrm{kg} / \mathrm{m}^{2}$ & $25.0 \pm 3.8$ & $24.4 \pm 2.3$ & $24.0 \pm 3.2$ & 0.344 \\
\hline $\mathrm{SBP}, \mathrm{mm} \mathrm{Hg}$ & $111.7 \pm 13.0$ & $110.4 \pm 13.8$ & $111.1 \pm 11.9$ & 0.884 \\
\hline $\mathrm{DBP}, \mathrm{mm} \mathrm{Hg}$ & $70.3 \pm 8.9$ & $69.0 \pm 8.4$ & $67.4 \pm 8.0$ & 0.343 \\
\hline Heart rate (beats/min) & $78.2 \pm 5.3$ & $77.9 \pm 6.1$ & $78.4 \pm 7.3$ & 0.447 \\
\hline Smoking, $\%(n)$ & $12(25.5 \%)$ & $11(26.8 \%)$ & $8(27.6 \%)$ & 0.839 \\
\hline \multicolumn{5}{|l|}{ Laboratory Findings } \\
\hline Glucose $(\mathrm{mg} / \mathrm{dl})$ & $86.6 \pm 12.0$ & $90.4 \pm 8.6$ & $90.2 \pm 9.1$ & 0.157 \\
\hline Total cholesterol (mg/dl) & $168.1 \pm 39.6$ & $159.5 \pm 37.4$ & $158.4 \pm 23.4$ & 0.304 \\
\hline LDL cholesterol (mg/dl) & $105.7 \pm 34.7$ & $96.0 \pm 19.8$ & $94.7 \pm 20.0$ & 0.133 \\
\hline HDL cholesterol (mg/dl) & $44.7 \pm 9.2$ & $41.9 \pm 13.5$ & $48.7 \pm 11.7$ & 0.055 \\
\hline Triglyceride $(\mathrm{mg} / \mathrm{dl})$ & $117.8 \pm 74.6$ & $108.1 \pm 55.3$ & $77.2 \pm 22.1^{\mathrm{a}}$ & 0.014 \\
\hline Creatinin $(\mathrm{mg} / \mathrm{dl})$ & $0.71 \pm 0.18^{\mathrm{b}}$ & $0.80 \pm 0.19$ & $0.76 \pm 0.14$ & 0.041 \\
\hline Hs-CRP (mg/dl) & $0.63 \pm 0.09$ & $0.61 \pm 0.08$ & $0.50 \pm 0.08^{\mathrm{c}}$ & $<0.001$ \\
\hline Calcium (mg/dl) & $9.2 \pm 0.5$ & $9.1 \pm 0.4$ & $9.2 \pm 0.5$ & 0.759 \\
\hline Parathyroid hormone $(\mathrm{pg} / \mathrm{ml})$ & $63.5 \pm 24.0$ & $61.8 \pm 36.0$ & $47.1 \pm 11.2^{\mathrm{d}}$ & 0.027 \\
\hline \multicolumn{5}{|l|}{ Echocardiographic Findings } \\
\hline Ejection Fraction (\%) & $61.8 \pm 3.8$ & $62.6 \pm 4.0$ & $62.2 \pm 3.8$ & 0.652 \\
\hline Aortic IMT (mm) & $1.83 \pm 0.70^{\mathrm{e}}$ & $1.38 \pm 0.37^{\mathrm{f}}$ & $0.99 \pm 0.50$ & $<0.001$ \\
\hline \multicolumn{5}{|l|}{ Clinical Diagnosis } \\
\hline ASD suspicion, $n(\%)^{*}$ & $30(63.8 \%)$ & $25(61.0 \%)$ & $19(65.5 \%)$ & 0.922 \\
\hline Atrial Fibrillation, $n(\%)^{*}$ & $11(23.4 \%)$ & $8(19.5 \%)$ & $7(24.1 \%)$ & 0.872 \\
\hline Valvular heart disease, $n(\%)^{*}$ & $6(12.8 \%)$ & $6(14.6 \%)$ & $5(17.2 \%)$ & 0.865 \\
\hline
\end{tabular}

\section{*Chi Square}

Abbreviations: VitD; 25-Hydroxyvitamin D, BMI; body mass index, SBP; systolic blood pressure, DBP; diastolic blood pressure, LDL; low density lipoprotein, HDL; high density lipoprotein, Hs-CRP; high sensitive C reactive protein, IMT; intima media thickness. Bold indicates statistically significant value.

${ }^{a} P=0.004$ vs. VitD $D_{\text {deficiency }}$ group, $\mathrm{p}=0.032$ vs. VitD $\mathrm{D}_{\text {insufficient }}$ group.

${ }^{\mathrm{b}} P=0.012$ vs. VitD $\mathrm{D}_{\text {insufficient }}$ group.

${ }^{c} P<0.001$ vs. VitD $D_{\text {deficiency }}$ group and $P=0.032$ vs. VitD $D_{\text {insufficient }}$ group.

${ }^{\mathrm{d}} P=0.011$ vs. VitD $\mathrm{D}_{\text {deficiency }}$ group and $P=0.026 \mathrm{vs}$. VitD $\mathrm{D}_{\text {insufficient }}$ group.

${ }^{\mathrm{e}} P<0.001$ vs. VitD $\mathrm{D}_{\text {insufficient }}$ group and $\mathrm{Vit}_{\text {normal }}$ group.

${ }^{\mathrm{f}} P=0.004$ vs. Vit $\mathrm{D}_{\text {normal }}$ group.

TABLE 2. Bivariate and multivariate relationships of $25(\mathrm{OH}) \mathrm{D}$

\begin{tabular}{lcrrr}
\hline & $\begin{array}{c}\text { Pearson } \\
\text { correlation } \\
\text { coefficient }\end{array}$ & $P$-value & $\begin{array}{c}\text { Standardized } \\
\beta \text { regression } \\
\text { coefficients }\end{array}$ & $P$-value \\
Variables & -0.315 & 0.001 & 0.005 & 0.943 \\
BMI $\left(\mathrm{kg} / \mathrm{m}^{2}\right)$ & -0.187 & 0.044 & -0.059 & 0.431 \\
LDL cholesterol $(\mathrm{mg} / \mathrm{dl})$ & -0.227 & 0.014 & -0.018 & 0.808 \\
Triglyceride $(\mathrm{mg} / \mathrm{dl})$ & -0.553 & $<0.001$ & -0.442 & $<0.001$ \\
Hs-CRP $(\mathrm{mg} / \mathrm{dl})$ & -0.612 & $<0.001$ & -0.499 & $<0.001$ \\
Aortic IMT $(\mathrm{mm})$ & & & & \\
\hline
\end{tabular}

showed that $25(\mathrm{OH}) \mathrm{D}$ level is independently associated with extent of IMT of thoracic aorta as well as hs-CRP.

In addition to its traditional effects on bone health, there is accumulating evidence to suggest that the vitamin $\mathrm{D}$ receptor has a broad spectrum of effects on various cell types including the endothelium (18), vascular smooth muscle (19), and cardiomyocytes (20). Vitamin D

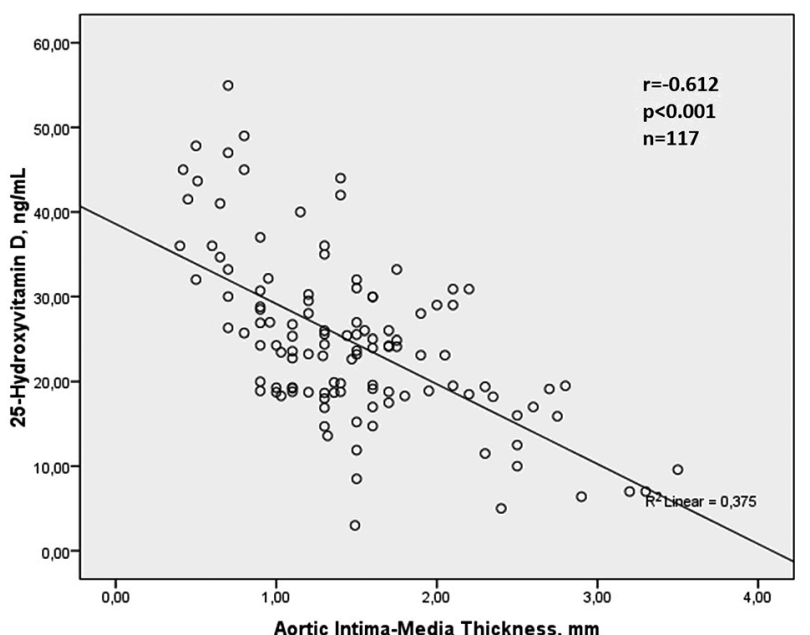

Fig. 2. Relationship between 25 -Hydroxyvitamin D level and aortic intima media thickness. 


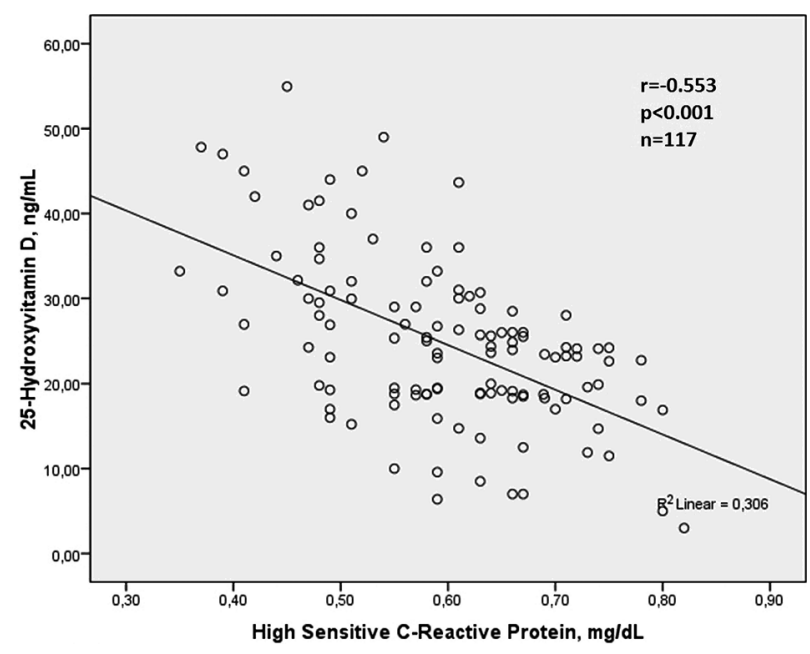

Fig. 3. Relationship between 25-Hydroxyvitamin D level and high sensitive $\mathrm{C}$ reactive protein.

receptor activation is thought to result in positive effects on cardiovascular system. The relationship between vitamin D insufficiency and coronary atherosclerosis is well known. Several large cross-sectional and longitudinal observational studies have shown that low levels of $25(\mathrm{OH}) \mathrm{D}$ are associated with a increased risk of coronary atherosclerosis $(7,21)$. In a previous study, Akin et al. reported that low-serum 25(OH)D level was associated with the severity of coronary atherosclerosis (22). It was shown that levels of $25(\mathrm{OH}) \mathrm{D}<30 \mathrm{ng} / \mathrm{ml}$ were associated with a greater risk of incident myocardial infarction even after adjustment for risk factors known to be associated with coronary artery disease (23).

Carotid IMT by B-mode ultrasonography has been utilized as a noninvasive surrogate marker to detect the presence, occurrence, and progression of subclinical atherosclerosis (24). Low $25(\mathrm{OH}) \mathrm{D}$ level is associated with carotid atherosclerosis assessed with carotid IMT (25). However, Harrington et al. (14) reported that thoracic aortic IMT has been reported as an earlier marker of preclinical atherosclerosis than carotid IMT. Moreover, the negative association between vitamin D levels and the prevalence of peripheral artery disease was confirmed in previous studies (25). An analysis of data from the NHANES has shown a strong negative correlation between low serum $25(\mathrm{OH}) \mathrm{D}$ level quartiles and prevalence of peripheral artery disease for each $10 \mathrm{ng} / \mathrm{ml}$ decrease in $25(\mathrm{OH}) \mathrm{D}$ level (26). On the other hand, the relationship between low 25(OH)D and aortic atherosclerosis assessed with thoracic aortic IMT was not investigated. Present study show that low $25(\mathrm{OH}) \mathrm{D}$ level is associated with increased aortic IMT, which reflects subclinical aortic atherosclerosis.

Mechanisms that explain the contribution of low $25(\mathrm{OH}) \mathrm{D}$ level to the atherosclerotic process have not been fully clarified. However, several mechanisms may be responsible for this relationship. Vitamin D interacts either directly with the vascular tree or indirectly through its association with cardiovascular risk factors (27). Vitamin D deficiency is viewed as an independent risk factor for atherosclerosis (27). Low levels of $25(\mathrm{OH}) \mathrm{D}$ are associated with traditional risk factors such as hypertension, obesity, dyslipidemia, and diabetes $(2-4,6,27)$ and regulates atherosclerotic biologic pathways (28). On the other hand, vitamin D may play a role in the pathogenesis of atherosclerosis - through a direct involvement in the process of plaque formation and progression $(27,29)$. Proliferation of vascular smooth muscle cells is a key step for plaque formation in atherosclerotic heart disease (30). Vitamin D modulates key processes in the pathogenesis of cardiovascular disease including vascular smooth muscle cell proliferation (29). In addition, it was shown that active vitamin D suppresses foamcell formation by reducing macrophage cholesterol uptake (31). Lower serum vitamin D levels may facilitate atherosclerosis by increasing macrophage cholesterol uptake. Inflammation is a key factor driving the processes of plaque formation, progression, and rupture in patients with atherosclerotic CAD (32). Vitamin D deficiency promotes stimulation of systemic and vascular inflammation (33). Recent studies have shown an inverse relationship between $25(\mathrm{OH}) \mathrm{D}$ levels and hs-CRP, which reflects to chronic inflammation (6). Present study showed that there was independent inverse relationship between 25(OH)D and hs-CRP. The relationship between lower serum vitamin D level and increased inflammation may mediate to more severe IMT. Also, the inverse relationships between Vitamin D with vascular calcification, endothelial dysfunction, and arterial stiffness may be effective on aortic atherosclerosis assessed with thoracic aortic IMT (27).

Patients with $25(\mathrm{OH}) \mathrm{D}$ deficiency had significantly higher body mass indexes compared to those with sufficient levels of $25(\mathrm{OH}) \mathrm{D}(6,34)$. This result supports the findings of the research which demonstrates sequestration of $25(\mathrm{OH}) \mathrm{D}$ in adipose tissue which results in decreased amount of circulating $25(\mathrm{OH}) \mathrm{D}(34)$. In present study, 25(OH)D was associated with BMI. However, similar relationship was not observed in multivariate regression analysis.

\section{Study Limitations}

The present study has some significant limitations: First, the patient population was selected from a diverse population with several disease states, although $25(\mathrm{OH}) \mathrm{D}$ was not related to diagnosis of any of these diseases. Second, coronary angiography was not performed in our patients although the diagnosis of coronary artery 
disease has been excluded according to clinical characteristics and patient history, electrocardiography, and treadmill exercise test. Third, it has been known that serum vitamin D levels vary with region, seasonality, and altitude due to possible effect of sunlight. The half life of vitamin D is approximately 3 weeks, but serum vitamin D levels may change throughout the day and season of the year. Finally, 1,25-dihydroxyvitamin D3 is the active metabolite. 1,25-dihydroxyvitamin $\mathrm{D} 3$ was not measured in present study. However, $25(\mathrm{OH}) \mathrm{D}$ has important autocrine and paracrine roles in the synthesis of 1,25dihydroxyvitamin D3 and determining intracellular levels of 1,25-dihydroxyvitamin D3 (35).

In conclusion, low $25(\mathrm{OH}) \mathrm{D}$ is independently associated with higher thoracic aortic IMT as well as hs-CRP in patients without clinical manifestation of atherosclerotic cardiovascular disease. Low $25(\mathrm{OH}) \mathrm{D}$ may play a role on both pathogenesis of subclinical thoracic atherosclerosis and chronic inflammatory process.

\section{REFERENCES}

1. Norman AW, Bouillon R, Whiting SJ, Vieth R, Lips P. 13th workshop consensus for vitamin D nutritional guidelines. J Steroid Biochem Mol Biol 2007;103:204-205.

2. Scragg R, Sowers M, Bell C. Serum 25-hydroxyvitamin D, diabetes, and ethnicity in the Third National Health and Nutrition Examination Survey. Diabetes Care 2004;27:2813-2818.

3. Lee P, Greenfield JR, Seibel MJ, Eisman JA, Center JR. Adequacy of vitamin D supplementation in severe deficiency is dependent on body mass index. Am J Med 2009;122:1056-1060.

4. Snijder MB, Lips P, Seidell JC, Visser M, et al. Vitamin D status and parathyroid hormone levels in relation to blood pressure: a population-based study in older men and women. J Intern Med 2007;261:558-565.

5. Reis JP, von Mühlen D, Michos ED, et al. Serum vitamin D, parathyroid hormone levels, and carotid atherosclerosis. Atherosclerosis 2009;207:585-590.

6. Kuloglu O, Gür M, Seker T, et al. Serum 25-hydroxyvitamin D level is associated with aortic distensibility and left ventricle hypertrophy in newly diagnosed type 2 diabetes mellitus. Diab Vasc Dis Res 2013:DOI: 10.1177/1479164113491125.

7. Lee JH, Gadi R, Spertus JA, Tang F, O'Keefe JH. Prevalence of vitamin $\mathrm{D}$ deficiency in patients with acute myocardial infarction. Am J Cardiol 2011;107:1636-1638.

8. Schierbeck LL, Jensen TS, Bang U, et al. Parathyroid hormone and vitamin D-Markers for cardiovascular and all cause mortality in heart failure. Eur J Heart Fail 2011;13:626-632.

9. Dobnig H, Pilz S, Scharnagl H, et al. Independent association of low serum 25-hydroxyvitamin $\mathrm{d}$ and 1,25-dihydroxyvitamin D levels with all-cause and cardiovascular mortality. Arch Intern Med 2008; 168:1340-1349

10. Tarcin O, Yavuz DG, Ozben B, et al. Vitamin D improves endothelial function in patients with type 2 diabetes mellitus and low vitamin D levels. Diabet Med 2008;25:320-325.

11. Lavie CJ, Lee JH, MIlani RV. Vitamin D and cardiovascular disease. J Am Coll Cardiol 2011;58:1547-1556.

12. Rohani $\mathbf{M}$, Jogestrand $\mathrm{T}$, Ekberg $\mathrm{M}$, et al. Interrelation between the extent of atherosclerosis in the thoracic aorta, carotid intima-Media thickness and the extent of coronary artery disease. Atherosclerosis 2005;179:311-316.
13. Belhassen L, Carville C, Pelle G, et al. Evaluation of carotid artery and aortic intima-Media thickness measurements for exclusion of significant coronary atherosclerosis in patients scheduled for heart valve surgery. J Am Coll Cardiol 2002;39: 1139-1144.

14. Harrington J, Peña AS, Gent R, Hirte C, Couper J. Aortic intima media thickness is an early marker of atherosclerosis in children with type 1 diabetes mellitus. J Pediatr 2010;156:237-241.

15. Holick MF. Vitamin D deficiency. N Engl J Med 2007;357:266-281.

16. Schiller NB, Shah PM, Crawford M, et al. Recommendations for quantitation of the left ventricle by two-dimensional echocardiography. American Society of Echocardiography Committee on Standards, Subcommittee on Quantitation of Two-Dimensional Echocardiograms. J Am Soc Echocardiogr 1989;2:358-367.

17. Nishino M, Masugata H, Yamada Y, et al. Evaluation of thoracic aortic atherosclerosis by transesophageal echocardiography. Am Heart J 1994;127:336-344.

18. Merke J, Milde P, Lewicka S, et al. Identification and regulation of 1,25-dihydroxyvitamin D3 receptor activity and biosynthesis of 1,25-dihydroxyvitamin D3. Studies in cultured bovine aortic endothelial cells and human dermal capillaries. J Clin Invest 1989;83:1903-1915.

19. Somjen D, Weisman Y, Kohen F, et al. 25-hydroxyvitamin D31alpha-hydroxylase is expressed in human vascular smooth muscle cells and is upregulated by parathyroid hormone and estrogenic compounds. Circulation 2005;111:1666-1671.

20. Wu-Wong JR. Potential for vitamin D receptor agonists in the treatment of cardiovascular disease. Br J Pharmacol 2009;158:395-412.

21. Wang TJ, Pencina MJ, Booth SL, et al. Vitamin D deficiency and risk of cardiovascular disease. Circulation 2008;117:503-511.

22. Akin F, Ayça B, Köse N, et al. Serum vitamin D levels are independently associated with severity of coronary artery disease. J Investig Med 2012;60:869-73.

23. Giovannucci E, Liu Y, Hollis BW, Rimm EB. 25-hydroxyvitamin $\mathrm{D}$ and risk of myocardial infarction in men: a prospective study. Arch Intern Med 2008;168:1174-1180.

24. Nguyen-Thanh HT, Benzaquen BS. Screening for subclinical coronary artery disease measuring carotid intima media thickness. Am J Cardiol 2009;104:1383-1388.

25. Reis JP, von Mühlen D, Michos ED, et al. Serum vitamin D, parathyroid hormone levels, and carotid atherosclerosis. Atherosclerosis 2009;207:585-590.

26. Melamed ML, Muntner P, Michos ED, et al. Serum 25hydroxyvitamin D levels and the prevalence of peripheral arterial disease: results from NHANES 2001 to 2004. Arterioscler Thromb Vasc Biol 2008;28:1179-1185.

27. Brewer LC, Michos ED, Reis JP. Vitamin D in atherosclerosis, vascular disease, and endothelial function. Curr Drug Targets 2011;12:54-60.

28. de Boer IH, Kestenbaum B, Shoben AB, et al. 25-hydroxyvitamin $\mathrm{D}$ levels inversely associate with risk for developing coronary artery calcification. J Am Soc Nephrol 2009;20:1805-1812.

29. Artaza JN, Contreras S, Garcia LA, et al. Vitamin D and cardiovascular disease: potential role in health disparities. J Health Care Poor Underserved 2011;22:23-38.

30. Zhang $\mathrm{C}$. The role of inflammatory cytokines in endothelial dysfunction. Basic Res Cardiol 2008;103:398-406.

31. Oh J, Weng S, Felton SK, et al. 1,25(OH)2 vitamin d inhibits foam cell formation and suppresses macrophage cholesterol uptake in patients with type 2 diabetes mellitus. Circulation 2009;120:687698.

32. Libby P. Vascular biology of atherosclerosis: Overview and state of the art. Am J Card 2003;91:3A-6A.

33. van Etten E, Mathieu C. Immunoregulation by 1,25dihydroxyvitamin D3: Basic concepts. J Steroid Biochem Mol Biol 2005;97:93-101. 
34. Lin E, Armstrong-Moore D, Liang Z, et al. Contribution of adipose tissue to plasma 25-hydroxyvitamin $\mathrm{D}$ concentrations during weight loss following gastric bypass surgery. Obesity (Silver Spring) 2011;19:588-594.
35. Oudshoorn C, van der Cammen TJ, McMurdo ME, van Leeuwen JP, Colin EM. Ageing and vitamin D deficiency: Effects on calcium homeostasis and considerations for vitamin $\mathrm{D}$ supplementation. $\mathrm{Br}$ J Nutr 2009;101:1597-1606. 